\title{
CATCHMENT STORAGE ESTIMATION BASED ON TOTAL RAINFALL-TOTAL LOSS RAINFALL RELATIONSHIP FOR 47 CATCHMENTS IN JAPAN
}

\author{
Intan SUPRABA ${ }^{1}$, Tomohito J. YAMADA ${ }^{2}$ \\ ${ }^{1}$ Member of JSCE, M.Sc., Doctoral Student, Graduate School of Engineering, Hokkaido University \\ (Kita 13, Nishi 8, Kita-ku, Sapporo, Hokkaido, 060-8628, Japan) \\ ${ }^{2}$ Member of JSCE, Ph.D., Associate Professor, Faculty of Engineering, Hokkaido University
}

(Kita 13, Nishi 8, Kita-ku, Sapporo, Hokkaido, 060-8628, Japan)

\begin{abstract}
One of the main objectives of research in hydrology is to improve the accuracy of catchment storage estimation for water resources management and flood prediction purposes. Rain water falling to the ground surface will either run off along the surface or infiltrate into the soil. The infiltrated water which is defined as loss rainfall can be used to estimate the potential catchment storage.

Total rainfall-total loss rainfall relationship has been developed to estimate catchment storage by using tanh function fitting curve for 47 catchments located in 16 prefectures in Japan between 2002 and 2011 (June to October). The obtained results indicate that runoff parameters in the tanh function represented by $a$ and $b$ parameters can be utilized to estimate the potential water storage for catchments having stabilized tanh curve type. Among 47 catchments, only $23.4 \%$ of the overall catchments have stabilized tanh curve types which are located in Honshu Island.
\end{abstract}

Key Words : Catchment Storage, Total Rainfall-Total Loss Rainfall, Runoff Parameters

\section{INTRODUCTION}

Total loss rainfall represents the spatial and temporal averaged behavior of the infiltration capacity during a rainfall event which is controlled by the soil properties, and is independent of the rainfall intensity ${ }^{1}$. Infiltration capacity analysis is necessary to estimate the potential catchment storage as one of the main variables in the general water balance equation. The water balance equation can be applied for water supply management and for water shortages prediction.

The non-linearity of surface runoff phenomena in the mountainous basins based on universal lumped kinematic wave model has been studied ${ }^{2,3), 4)}$. Runoff in mountainous basins are uniquely determined by model parameters concerning slope gradient, slope length, the thickness of surface soil layer, unsaturated hydraulic conductivity, and effective porosity ${ }^{3), 4)}$.

Other methods for estimating water storage capacity is to use a scatter plot of measured interception versus precipitation, and then validating the result by measuring water storage using microwave transmission with a vertically moving system $^{5)}$ and by estimating spatial mean volumetric soil water content $(\theta)$ using measured $\theta$ from the Most Time Stable Locations (MTSLs) to estimate mean $\theta$ in an adjacent or distant area while negating the impact of variability in soil, vegetation, and topographic properties ${ }^{6}$.

The purpose of this study is to estimate the potential catchment storage by utilizing hourly rainfall and hourly runoff observation data for 47 gauged catchments located in 16 prefectures in Japan (see Table 1). The potential catchment storage is expressed by $a$ parameter and the curve gradient which controls the $a$ parameter is expressed by $b$ parameter. The values of $a$ and $b$ parameters are obtained by plotting total rainfall-total loss rainfall using tanh function fitting curve.

Section 2 describes the research methodology. Section 3 shows the geographical distribution of total rainfall and total loss rainfall relationship. Section 4 shows the relationship of $a$ and $b$ values, and conclusions are explained in Section 5. 


\section{METHODOLOGY}

\section{(1)Data}

Hourly rainfall and hourly runoff data for 47 catchments located in 16 prefectures in Japan are obtained from Ministry of Land, Infrastructure, and Transport (MLIT) website ${ }^{7)}$. The study period is during summer time from month of June to month of October for 10 years (2002-2011).
Table 1 presents the list of 47 catchments and their catchment areas. The information of average daily runoff and obtained results ( $a$ values, $b$ values, and curve types) for each catchment is also presented in Table 1. The average daily runoff is obtained by averaging total daily runoff within 10 years from month of June to month of October.

Table 1 List of 47 catchments in 16 prefectures in Japan ( $a$ denotes the potential catchment storage, $b$ denotes the curve gradient, and curve type is classified into 3 groups i.e. linear, non-stabilized tanh curve, and stabilized tanh curve)

\begin{tabular}{|c|c|c|c|c|c|c|c|}
\hline NO. & DAM NAME & $\begin{array}{c}\text { PREFECTURE } \\
\text { (Latitude, Longitude) }\end{array}$ & $\begin{array}{c}\text { CATCHMENT } \\
\text { AREA } \\
\left(\mathrm{km}^{2}\right)\end{array}$ & $\begin{array}{c}\text { AVERAGE } \\
\text { DAILY } \\
\text { RUNOFF } \\
\left(\mathrm{m}^{3} / \mathrm{s}\right) \\
\end{array}$ & $a$ & $b$ & CURVE TYPE \\
\hline 1 & Houheikyou & Hokkaido $(42.92,141.15)$ & 136.10 & 171.41 & 361.70 & 0.00213 & Non stabilized tanh curve \\
\hline 2 & Iwaonai & Hokkaido $(44.12,142.71)$ & 341.58 & 297.56 & 613.89 & 0.00131 & Non stabilized tanh curve \\
\hline 3 & Izarigawa & Hokkaido $(42.85,141.45)$ & 113.25 & 115.89 & 1810.99 & 0.00047 & Linear \\
\hline 4 & Jyouzankei & Hokkaido $(42.98,141.16)$ & 103.59 & 78.07 & 765.76 & 0.00092 & Non stabilized tanh curve \\
\hline 5 & Kanayama & Hokkaido $(43.13,142.44)$ & 410.81 & 449.21 & 760.62 & 0.00103 & Non stabilized tanh curve \\
\hline 6 & Katsurazawa & Hokkaido $(43.24,142)$ & 162.50 & 201.57 & 277.97 & 0.00191 & Non stabilized tanh curve \\
\hline 7 & Nibutani & Hokkaido $(42.63,142.15)$ & 1155.45 & 1271.19 & 322.15 & 0.00253 & Non stabilized tanh curve \\
\hline 8 & Pirika & Hokkaido $(42.47,140.19)$ & 114.44 & 191.84 & 660.99 & 0.00099 & Non stabilized tanh curve \\
\hline 9 & Satsunaigawa & Hokkaido $(42.59,142.92)$ & 116.63 & 270.08 & 454.01 & 0.00100 & Non stabilized tanh curve \\
\hline 10 & Taisetsu & Hokkaido $(43.68,143.04)$ & 289.26 & 400.36 & 4025.39 & 0.00021 & Linear \\
\hline 11 & Takisato & Hokkaido $(43.44,142.29)$ & 1369.37 & 1411.59 & 1290.17 & 0.00051 & Linear \\
\hline 12 & Tokachi & Hokkaido $(43.24,142.94)$ & 598.24 & 332.79 & 5037.92 & 0.00016 & Linear \\
\hline 13 & Aseishigawa & Aomori $(40.6,140.69)$ & 227.53 & 274.79 & 1538.63 & 0.00036 & Non stabilized tanh curve \\
\hline 14 & Tamagawa & Akita $(39.83,140.64)$ & 283.59 & 549.45 & 48.05 & 0.01217 & Stabilized tanh curve \\
\hline 15 & Gosho & Iwate $(39.69,141.03)$ & 635.17 & 1027.06 & 1244.27 & 0.00044 & Non stabilized tanh curve \\
\hline 16 & Ishibuchi & Iwate $(39.11,140.9)$ & 145.75 & 269.23 & 53.01 & 0.01137 & Stabilized tanh curve \\
\hline 17 & Shijushida & Iwate $(39.75,141.15)$ & 1178.38 & 1043.20 & 124.25 & 0.00342 & Non stabilized tanh curve \\
\hline 18 & Tase & Iwate $(39.34,141.32)$ & 727.63 & 602.94 & 79.07 & 0.00824 & Non stabilized tanh curve \\
\hline 19 & Yuda & Iwate $(39.3,140.89)$ & 576.45 & 885.85 & 51.22 & 0.01126 & Stabilized tanh curve \\
\hline 20 & Gassan & Yamagata $(38.58,139.89)$ & 237.47 & 244.02 & 2692.35 & 0.00023 & Linear \\
\hline 21 & Sagae & Yamagata $(38.46,140.04)$ & 227.58 & 565.79 & 176.41 & 0.00198 & Non stabilized tanh curve \\
\hline 22 & Shirakawa & Yamagata $(37.97,139.92)$ & 205 & 267.00 & 62.53 & 0.00738 & Non stabilized tanh curve \\
\hline 23 & Kamafusa & Miyagi $(38.2,140.7)$ & 196.09 & 267.08 & 49.14 & 0.01156 & Stabilized tanh curve \\
\hline 24 & Naruko & Miyagi $(38.75,140.7)$ & 208.54 & 329.11 & 67.56 & 0.00740 & Non stabilized tanh curve \\
\hline 25 & Shichikashuku & Miyagi $(37.96,140.51)$ & 230.61 & 210.19 & 55.62 & 0.01216 & Stabilized tanh curve \\
\hline 26 & Miharu & Fukushima $(37.4,140.47)$ & 227.63 & 146.91 & 181.27 & 0.00367 & Non stabilized tanh curve \\
\hline 27 & Sagurigawa & Niigata $(37.52,139)$ & 61.36 & 132.52 & 1114.41 & 0.00049 & Non stabilized tanh curve \\
\hline 28 & Kawaji & Tochigi $(36.9,139.69)$ & 320.74 & & 765.77 & 0.00121 & Non stabilized tanh curve \\
\hline 29 & Fujiwara & Gunma $(36.8,139.04)$ & 400.20 & 816.73 & 824.23 & 0.00064 & Non stabilized tanh curve \\
\hline 30 & Kusaki & Gunma $(36.54,139.37)$ & 263.85 & 448.58 & 739.23 & 0.00086 & Non stabilized tanh curve \\
\hline 31 & Naramata & Gunma $(36.88,139.08)$ & 95.40 & 101.70 & 753.24 & 0.00099 & Non stabilized tanh curve \\
\hline 32 & Shimokubo & Gunma $(36.13,139.02)$ & 323.65 & 287.59 & 413.12 & 0.00186 & Non stabilized tanh curve \\
\hline 33 & Sonohara & Gunma $(36.64,139.18)$ & & 369.84 & 625.13 & 0.00139 & Non stabilized tanh curve \\
\hline 34 & Yagisav & Gunma $(36.91,139.06)$ & 165.54 & 405.06 & 345.41 & 0.00190 & Stabilized tanh curve \\
\hline 35 & Futase & Saitama $(35.94,138.91)$ & 170.58 & 166.83 & 528.18 & 0.00137 & Non stabilized tanh curve \\
\hline 36 & Urayama & Saitama $(35.95,139.05)$ & 52.14 & 54.83 & 125.98 & 0.00709 & Stabilized tanh curve \\
\hline 37 & Koshibu & Nagano $(35.61,137.98)$ & 289.57 & 236.85 & 359.60 & 0.00246 & Stabilized tanh curve \\
\hline 38 & Makio & Nagano $(35.82,137.6)$ & 307.79 & 479.82 & 436.91 & 0.00164 & Stabilized tanh curve \\
\hline 39 & Misogawa & Nagano $(35.98,137.77)$ & 54.21 & 84.57 & 71.32 & 0.01126 & Non stabilized tanh curve \\
\hline 40 & Miwa & Nagano $(35.81,138.08)$ & 311.03 & 383.34 & 826.13 & 0.00099 & Non stabilized tanh curve \\
\hline 41 & Kuzuryu & Fukui $(35.89,136.69)$ & 390.36 & 508.59 & 114.48 & 0.00569 & Stabilized tanh curve \\
\hline 42 & Agigawa & Gifu $(35.42,137.43)$ & 81.8 & 122.39 & 47.43 & 0.01217 & Non stabilized tanh curve \\
\hline 43 & Iwaya & Gifu $(35.76,137.16)$ & 1695.75 & 744.99 & 185.56 & 0.00342 & Non stabilized tanh curve \\
\hline 44 & Yokoyama & Gifu $(35.59,136.46)$ & 470.71 & 662.16 & 1419.33 & 0.00049 & Non stabilized tanh curve \\
\hline 45 & Shintoyone & Aichi $(35.13,137.76)$ & 111.44 & 356.46 & 486.60 & 0.00092 & Non stabilized tanh curve \\
\hline 46 & Yahagi & Aichi $(35.24,137.42)$ & 504.62 & 834.21 & 767.03 & 0.00099 & Non stabilized tanh curve \\
\hline 47 & Hachisu & Mie $(34.38,136.21)$ & 80.9 & 211.17 & 411.26 & 0.00175 & Stabilized tanh curve \\
\hline
\end{tabular}




\section{(2) Streamflow hydrograph separation}

A hydrograph separation technique to separate a streamflow hydrograph into base flow and surface runoff components was introduced by U.S. Geological Survey (USGS). The technique is called local minimum method and was developed by Pettyjohn and Henning in the year $1979^{8)}$. The original hourly rainfall and hourly runoff data are converted into daily values format. The runoff refers to the dam inflow (inlet flow).

The local minimum method checks each day to determine if it is the lowest discharge in a specific given interval before and after the day being considered. If it is, then it is a local minimum and is connected by straight lines to adjacent local minimums. The base flow values for each day between local minimums are estimated by linear interpolations $^{8), 9)}$ (see Fig.1).

The duration of surface runoff is calculated from the empirical relation ${ }^{8)}$ :

$$
N=A^{0.2}
$$

,where $N$ is the number of days after which surface runoff ceases, and $A$ is the drainage area in square miles. The interval used to determine the lowest discharge is specified as below:

$$
I=0.5\left(2 N^{*}-1\right)
$$

,where $I$ is the interval used for hydrograph separation (days), and $2 N^{*}$ is the odd integer between 3 and 11 and nearest to $2 N^{8)}$.

HYDROGRAPH SEPARATION OF JYOUZANKEI DAM (JUNE-OCTOBER, YEAR 2002-2011)

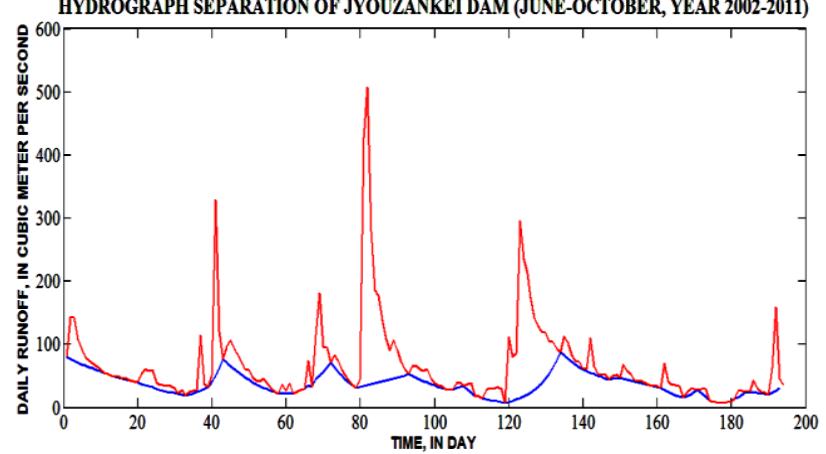

Fig.1 Streamflow hydrograph separation by using local minimum method. The surface runoff is denoted by red line, whereas the base flow is denoted by blue line.

\section{(3)Relationship between total rainfall and total loss rainfall}

Total rainfall is defined as the total amount of rainfall within 1 rainfall event, whereas total surface runoff is defined as the total amount of surface runoff within 1 rainfall event. The surface runoff (excess rainfall intensity) is subtracted from the actual rainfall intensity (total rainfall) to obtain the loss rainfall. Total loss rainfall is defined as total amount of rainfall that infiltrates into the ground.
The numbering of rainfall events is determined by utilizing surface runoff data after obtaining rainfall events as the output of a streamflow hydrograph separation.

Total rainfall and total loss rainfall for 47 catchments are plotted by using tanh function to obtain $a$ and $b$ values as runoff parameters ${ }^{3), 4)}$.

$$
y=a \tanh (b x)
$$

,where $y$ is the total loss rainfall (mm), $x$ is the total rainfall (mm), and $a$ and $b$ are runoff parameters.

\section{GEOGRAPHICAL DISTRIBUTION OF TOTAL RAINFALL AND TOTAL LOSS RAINFALL RELATIONSHIP}

\section{(1)Total rainfall and total loss rainfall relationship for 47 catchments \\ The obtained results by applying Eq.(3) for 47 catchments are plotted in Fig.2.}
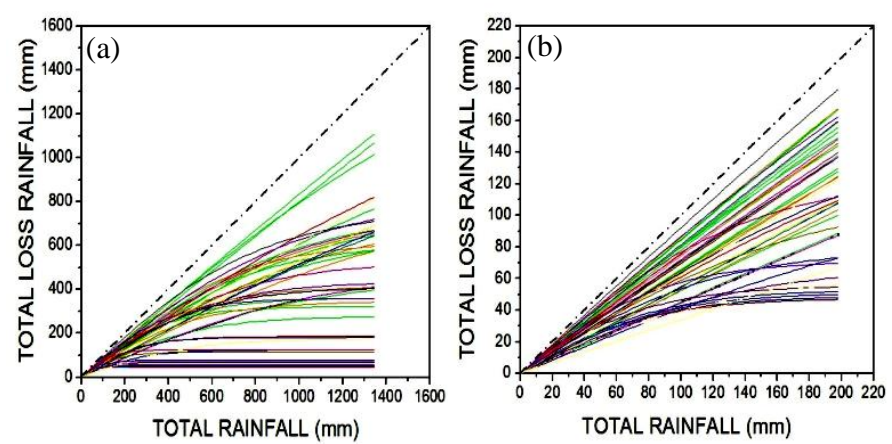

Fig.2 (a) Relationship between total rainfall and total loss rainfall for different areas: green lines denote Hokkaido Prefecture, yellow line denotes Aomori Prefecture, cyan line denotes Akita Prefecture, dark blue lines denote Iwate Prefecture, light yellow lines denote Yamagata Prefecture, purple lines denote Miyagi Prefecture, navy line denotes Fukushima Prefecture, dark cyan line denotes Niigata Prefecture, dark gray line denotes Tochigi Prefecture, orange lines denote Gunma Prefecture, pink lines denote Saitama Prefecture, violet lines denote Nagano Prefecture, dark yellow line denotes Fukui Prefecture, red lines denote Gifu Prefecture, magenta lines denote Aichi Prefecture, black line denotes Mie Prefecture.

(b) All of catchments show linear curve up to $60 \mathrm{~mm}$ total amount of rainfall in 1 rainfall event.

Fig.2a shows catchments located in the same prefecture can have different curve types. All of catchments show linear curve up to $60 \mathrm{~mm}$ total amount of rainfall in 1 rainfall event (see Fig.2b). This implies that for overall catchments, when there is a rainfall event, at least $60 \mathrm{~mm}$ total amount of rainfall can infiltrate into the ground and there is no amount of rainfall that contributes to surface runoff. 
(a)

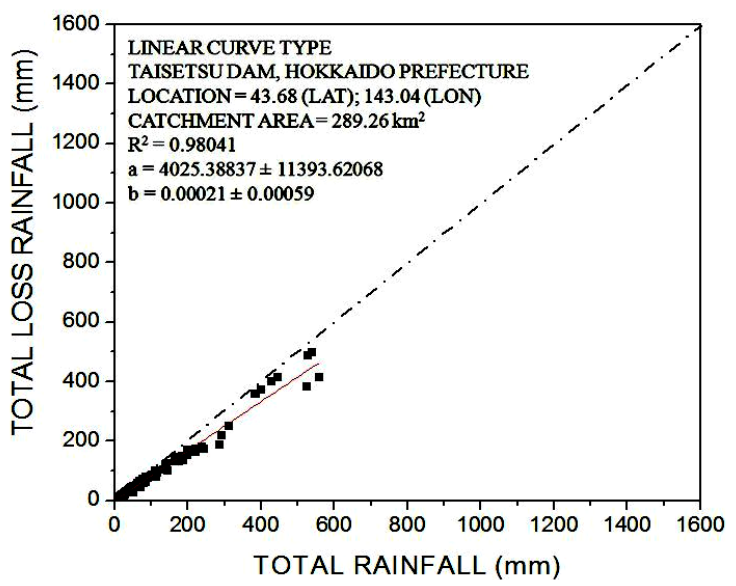

(b)

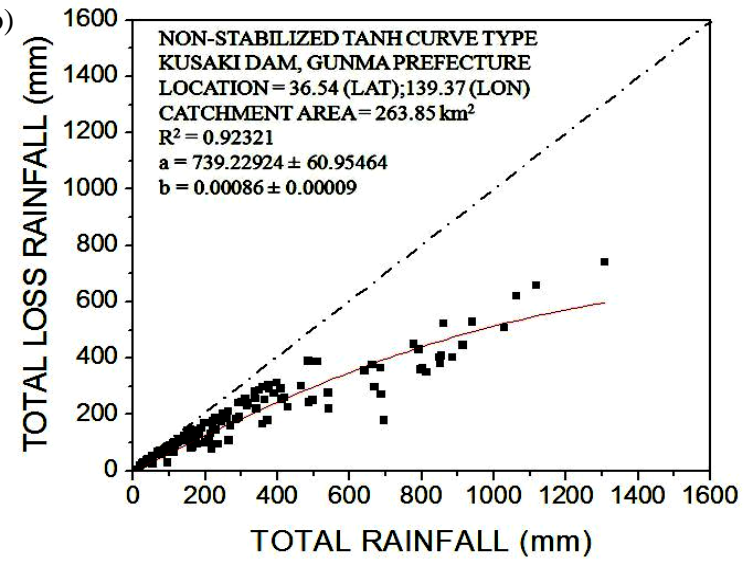

(c)

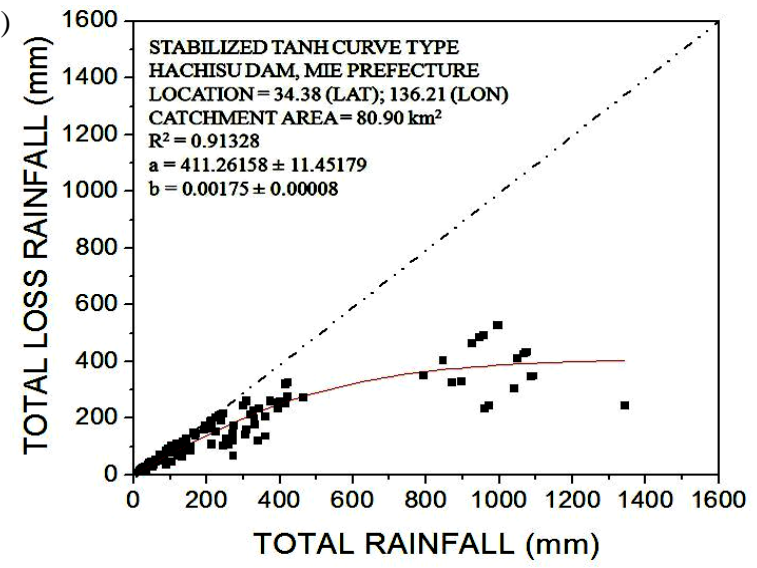

Fig.3 (a) Linear curve type of Taisetsu dam in Hokkaido prefecture. (b) Non-stabilized tanh curve type of Kusaki dam in Gunma prefecture. (c) Stabilized tanh curve type of Hachisu dam in Mie prefecture.

As shown in Fig.3a, Taisetsu dam catchment in Hokkaido prefecture has never experienced heavy rainfall events during the last 10 years between June and October. Based on 154 rainfall events occurred within the last 10 years, in average $83.06 \%$ total amount of rainfall infiltrated into the ground, and only $16.94 \%$ became surface runoff. Therefore, the curve shows linear type because the infiltration is dominant over the surface runoff.

Based on 159 rainfall events occurred at Kusaki dam catchment in Gunma prefecture, in average
$70.94 \%$ total amount of rainfall infiltrated into the ground, and only $29.06 \%$ became surface runoff (see Fig.3b). In terms of frequency, the number of heavy rainfall events having similar values of total rainfall amount was not adequate for making stabilized tanh curve. Thereby, the curve shows transition curve from linear to stabilized tanh curve which is named non-stabilized tanh curve.

For Hachisu dam catchment in Mie prefecture, based on 162 rainfall events, in average $67.37 \%$ total amount of rainfall infiltrated into the ground, and $32.63 \%$ became direct runoff. In terms of frequency, there were some heavy rainfall events in the range of $794 \mathrm{~mm}$ and $1345 \mathrm{~mm}$ of total rainfall amount which occurred for 23 times. These rainfall events were considered heavy rainfall events compared with normal events which ranged from 3 $\mathrm{mm}$ and $464 \mathrm{~mm}$. Therefore, adequate number of heavy rainfall events can make a stabilized tanh curve type as seen in Fig.3c.

When the curve has reached its stable condition, the total loss rainfall tends to be constant for any kind of total rainfall. It means that the catchments soils have become saturated and the major portion of rainfall will become surface runoff. Therefore, $a$ parameter as the maximum height of a stabilized tanh curve can be used to estimate the potential amount of rain water which can be stored in the respective catchment.

The same amount of total rainfall in 1 rainfall event may result in different amount of total loss rainfall (see Fig.3a-3c). The results have shown that $a$ parameter obtained by plotting total rainfall and total loss rainfall using tanh function contains the value of standard deviation ( $1 \sigma)$ (see Fig.4).

This standard deviation value represents the initial soil moisture condition of the respective catchment. The negative value of standard deviation can represent the wet initial soil moisture condition, whereas the positive value of standard deviation can represent the dry initial soil moisture condition.

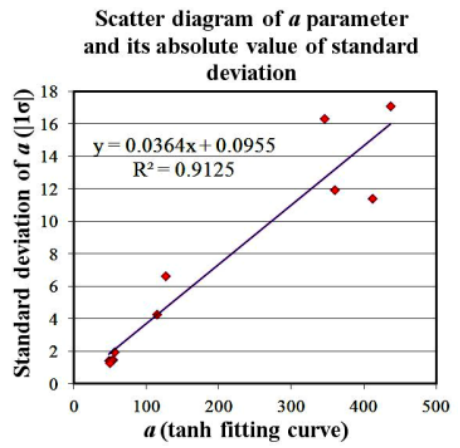

Fig.4 Scatter diagram of $a$ parameter and its absolute value of standard deviation for catchments having stabilized tanh curve types. 
Geographical distribution of $a$ parameter is shown in Fig.5.

The range of $\boldsymbol{a}$ values for catchments having:

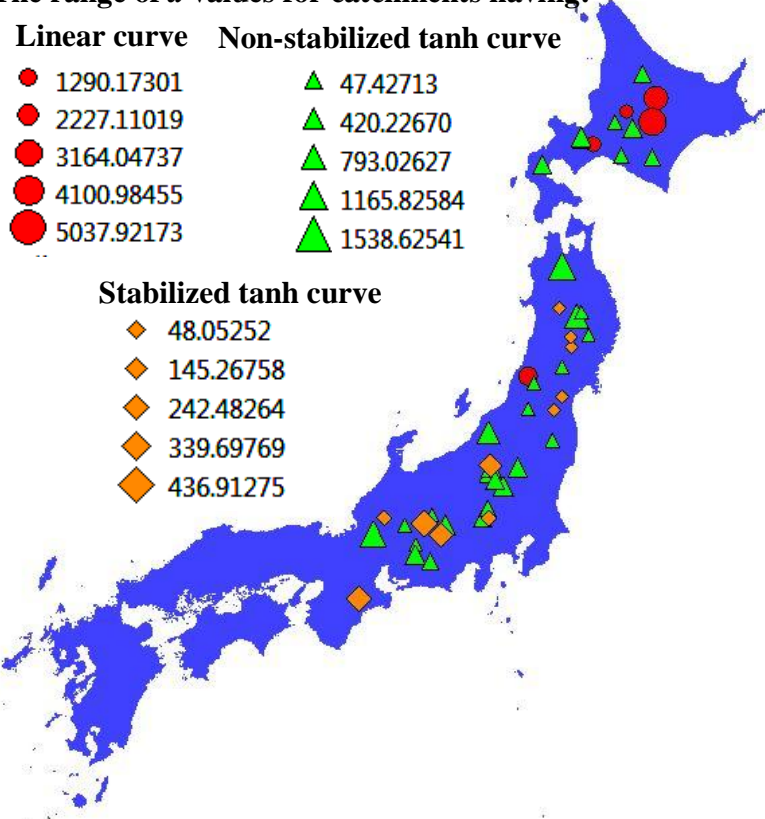

Fig.5 Geographical distribution of $a$ parameter (red circles denote 5 catchments having linear curve, green triangles denote 31 catchments having non-stabilized tanh curve, and orange diamonds denote 11 catchments having stabilized tanh curve).

\section{RELATIONSHIP OF $a$ AND $b$ VALUES}

\section{(1)Scatter diagram of $a$ and $b$ parameters}

The values of $a$ and $b$ parameters are obtained by plotting total rainfall $(\mathrm{mm})$ and total loss rainfall (mm) using Eq.(3). Scatter diagram of $a$ and $b$ parameters for 47 catchments is shown in Fig. 6.

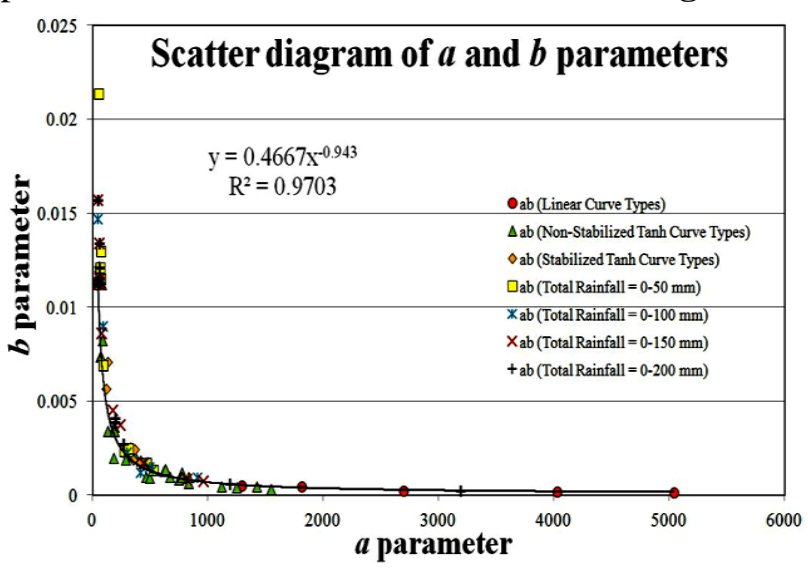

Fig.6 Scatter diagram of $a$ and $b$ parameters (red circles denote catchments having linear curve, green triangles denote catchments having non-stabilized tanh curve, and orange diamonds denote catchments having stabilized tanh curve). The values of $a$ and $b$ for 11 catchments having stabilized tanh curve are plotted in the curve for different range of total rainfall amount (yellow square: 0-50 mm, blue cross: $0-100 \mathrm{~mm}$, red cross: $0-150 \mathrm{~mm}$, black plus: $0-200 \mathrm{~mm}$ ).
Based on the result showed in Fig.6, $b$ parameter is a function of $a$ parameter based on empirical equation as follows:

$$
\begin{aligned}
b & =0.4667 \times a^{-0.943} \\
a & =(b / 0.4667)^{-1.0604}
\end{aligned}
$$

Hence Eq.(3) can be rewritten as follows:

$$
y=a \tanh \left(0.4667 a^{-0.943} x\right)
$$

,where $y$ is the total loss rainfall (mm), $x$ is the total rainfall (mm), and $a$ is potential catchment storage.

\section{(2)Estimation of $a$ value for different amount of total rainfall in 1 rainfall event}

As shown in Fig.6, $a$ and $b$ values obtained from tanh fitting curve for 11 catchments having stabilized tanh curve are overplotted in the curve fitting for different range of total amount of rainfall. Results show that the values are well fitted to the curve. Therefore, the obtained empirical equation can be utilized to estimate the value of $a$ parameter regardless the total amount of rainfall occurred in 1 rainfall event.

\section{(3) Validation of obtained empirical equation}

The validation of obtained empirical equation has been done by comparing the $a$ values obtained from Eq.(5) against the $a$ values obtained from tanh fitting curves for catchments having stabilized tanh curve type.
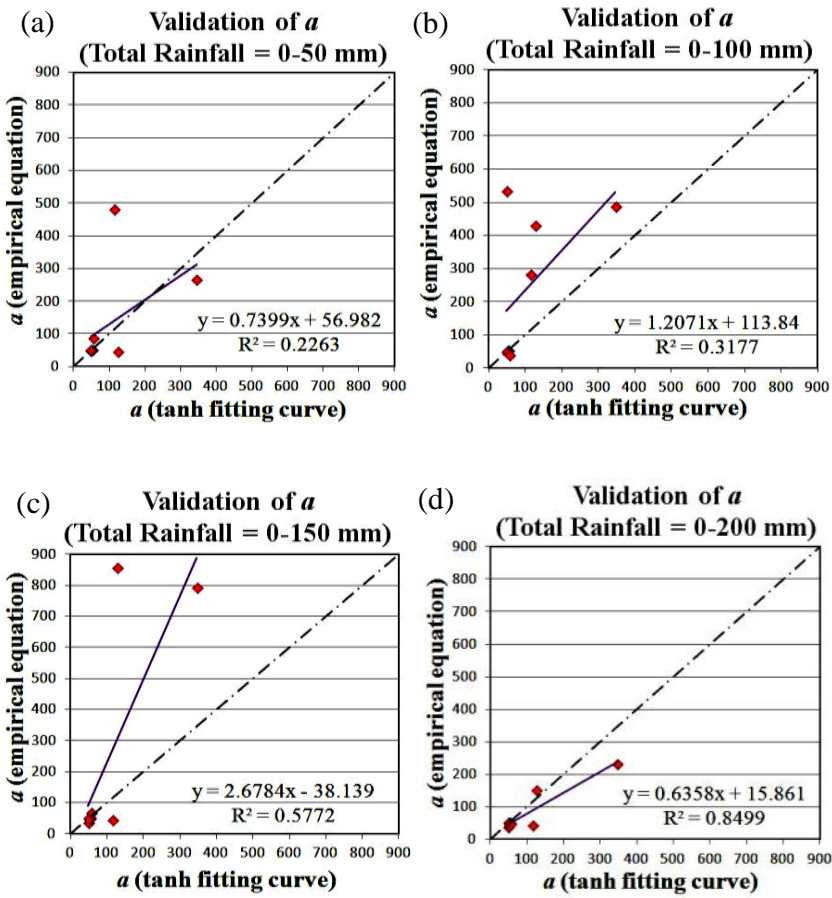

Fig.7 Validation of $a$ for total rainfall ranged from

(a) $0 \mathrm{~mm}$ to $50 \mathrm{~mm}$ (b) $0 \mathrm{~mm}$ to $100 \mathrm{~mm}$

(c) $0 \mathrm{~mm}$ to $150 \mathrm{~mm}$ (d) $0 \mathrm{~mm}$ to $200 \mathrm{~mm}$. 
The validation has been done for several cases i.e. for maximum total amount of rainfall within 1 rainfall event ranged from $0 \mathrm{~mm}$ to $50 \mathrm{~mm}, 0 \mathrm{~mm}$ to $100 \mathrm{~mm}, 0 \mathrm{~mm}$ to $150 \mathrm{~mm}$, and $0 \mathrm{~mm}$ to $200 \mathrm{~mm}$ (see Fig.7a, b, c, and d, respectively).

Fig.7a-7d indicate that $a$ values obtained from empirical equation show good correlation with $a$ values obtained from tanh fitting curves for catchments having stabilized tanh curve types when there is relatively high total rainfall amount.

\section{CONCLUSIONS}

Conclusions of the current research results can be summarized as follows:

- Out of 47 catchments located in 16 prefectures in Japan, 5 catchments have linear curve, 31 catchments have non-stabilized tanh curve, and only 11 catchments have stabilized tanh curve. It means majority of catchments in Japan have not experienced saturated condition yet and have the capability to store rain water whenever there is a rainfall event.

- The minimum catchment storage in 1 rainfall event for overall catchments is approximately 60 mm amount of rain water.

- Parameter $a$ in the tanh function is the maximum height of a stabilized tanh curve which can represent the potential catchment storage. Further studies are needed to explain the physical meaning of $a$ parameter in relation to catchment characteristics (soil types, terrain types, rock types, and land use types).

- Parameters $a$ and $b$ for stabilized tanh curve can be correlated by using an empirical equation i.e. $b=0.4667 * a^{-0.943}$ where $a$ and $b$ are runoff parameters. This empirical equation can be applied regardless the total amount of rainfall occurred in 1 rainfall event.

- Loss of infiltrated rainfall is independent of the total amount of rainfall but correlated to the initial soil moisture content. Total loss rainfall is dependent of potential catchment storage which is represented by $a$ parameter.

- The obtained empirical equation can be used to estimate the value of $a$ during saturated condition if there is longer data set which contains heavy rainfall events.
ACKNOWLEDGMENT: This study was partially supported by Research Program on Climate Change Adaptation (RECCA), MEXT, Japan, the MEXT SOUSEI program (theme C-i-C), the Integrated Study Project on Hydro-Meteorological Prediction and Adaptation to Climate Change in Thailand (IMPAC-T), the JST-JICA, and the CREST/JST.

\section{REFERENCES}

1) Brutsaert, W.: An Introduction of Hydrology, Cambridge University Press, pp.343-344, 2005.

2) Yamada, T., Yamazaki, K.: The Influence of The Distribution of Field Moisture Capacity on Runoff, JSCE Hydraulic Journal, Vol.27, pp.385-392, 1983.

3) Yamada, T.: Studies on Non-Linear Runoff in Mountainous Basins, JSCE Hydraulic Journal, Vol.47, pp.259-264, 2003.

4) Kure, S., Yamada, T.: A Study on The Non-Linearity of Runoff Phenomena and Estimation of Effective Rainfall, Proceedings of the $2^{\text {nd }}$ Asia Pacific Association of Hydrology and Water Resources Conference, Vol.2, pp.76-85, 2004.

5) Klaassen, W., Fred, B., E. de, W.: Water storage and evaporation as constituents of rainfall interception, Journal of Hydrology, Vol.212-213, pp.36-50, 1996.

6) Wei, H., Ming, A. S., Mei, T. H., Dong, L. S., Bing, C. S.: Mean soil water content estimation using measurements from time stable locations of adjacent or distant areas, Journal of Hydrology, Vol.497, pp.234-243, 2013.

7) Water Information System: Ministry of Land, Infrastructure, and Transport (MLIT), Japan, http://www1.river.go.jp/.

8) Sloto, R. A., Crouse, M. Y.: Hysep: A Computer Program for Streamflow Hydrograph Separation and Analysis, U.S. Geological Survey, Water-Resources Investigations Report 96-4040, 1996.

9) Dukic, V.: Modelling of base flow of the basin of Kolubara river in Serbia, Journal of Hydrology, Vol.327, pp.1-12, 2006.

10)Hino, M., Odaka, Y., Nadaoka, K. and Sato, A.: Effect of Initial Soil Moisture Content on The Vertical Infiltration Process: A Guide To The Problem of Runoff-Ration and Loss , Journal of Hydrology, Vol.102, pp.267-284, 1988.

11)Tachikawa, Y., Nawarathna, B., Vieux, B., Takara, K.: Hydrologic Prediction Using Weather Radar Information and Distributed Hydrologic Modelling, The XXIII General Assembly of the International Union of Geodesy and Geophysics, Sapporo, Japan, 2003.

12)Shiiba, M., Takasao, T., Nakakita, E.: Investigation of short term rainfall prediction method by a translation model, Proceedings of the $28^{\text {th }}$ Annual Conference on Hydraulics, JSCE, pp.423-428. 